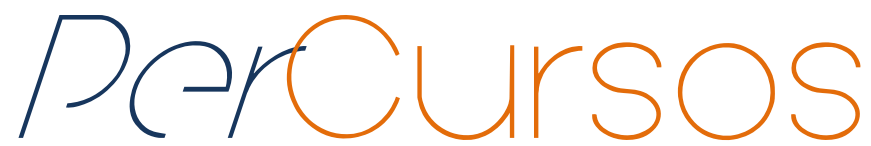

\title{
Estudos da memória: em foco uma discussão teórica da importância de suas diferentes abordagens
}

\section{Resumo}

A proposta do presente trabalho é apresentar uma discussão conceitual e terminológica relativa à temática memória, entre elas: memória social, memória organizacional e memória institucional. O estudo é de cunho teórico e o tipo de pesquisa é bibliográfico. Como fontes de pesquisa, foram utilizados: livros, bibliotecas digitais de teses e dissertações no âmbito do país e o Portal de Periódicos da CAPES. Este estudo está em andamento e faz parte da pesquisa "A memória e a constituição de bases de conhecimento nos ambientes institucionais". Como resultado parcial, observa-se que a questão da "memória" é estudada por diferentes áreas do conhecimento, como: Psicologia, Neurociências, História entre outras; o conceito de memória organizacional é estudado pela área da Administração e Sistemas de Informação; o conceito de memória institucional é mais estudado pela área de Comunicação Empresarial enfocando a história da empresa. Além disso, observa-se o uso de outro termo, memória social, utilizado pelas áreas de Ciência da Informação e História.

Palavras-chave: Estudos da Memória. Memória Social. Memória Organizacional. Memória Institucional.

\author{
Letícia Gorri Molina \\ Doutora em Ciência da \\ Informação pela UNESP. \\ Professora da Universidade \\ Estadual de Londrina - Brasil. \\ leticiamolina@uel.br
}

\footnotetext{
Para citar este artigo:

MOLINA, Letícia Gorri. Estudos da memória: em foco uma discussão teórica da importância de suas diferentes abordagens. Revista PerCursos. Florianópolis, v. 15, n.29, p. 07 - 38. jul./dez. 2014.
} 


\title{
Memory Studies: focus on a theoretical discussion about the importance of their different approaches
}

\begin{abstract}
The proposal of present paper is to present a conceptual and terminological discussion relative memory to the theme, including: social memory, organizational memory, institutional memory. The study is theoretical focus and the research kind is bibliographical. As research sources were utilized: books, digital libraries of theses and dissertations in the scope of the country and CAPES Journals Portal. This study is in course and is part of research "Memory and the constitution of knowledge bases in institutional environments". As the partial results, observes that the question about "memory" is studied by different areas of knowledge: Psychology, Neurosciences, History and others; the concepts about organizational memory are studied by Administration and Information Systems areas; the concept of institutional memory is more studied by Business Communication area focusing the company history. Beyond that, observes the use of another term, social memory, utilized by Information Science and History areas.
\end{abstract}

Keywords: Memory Studies. Social Memory. Organizational Memory. Institutional Memory. 


\section{Introdução}

O tema "memória" tem sido estudado por diferentes áreas do conhecimento, assim como apresenta diferentes faces, de acordo com o desenvolvimento da sociedade. Diante disso, temos: memória oral, na sociedade sem escrita; memória oral e memória escrita, na idade média; memória escrita, com o surgimento da imprensa e com a alfabetização; memória em expansão, com o surgimento da informática e, consequentemente, da memória artificial.

Segundo um estudo realizado por Erll e Nünning (2008, p.1) constata-se que nas últimas duas décadas, a relação entre cultura e memória tem sido discutidas em várias partes do mundo, de forma interdisciplinar, envolvendo diversos campos de pesquisa como as áreas de História, Sociologia, Arte, Literatura e Mídias, Filosofia, Teologia, Psicologia e Neurociência, reunindo os campos das humanidades, estudos sociais e ciências naturais.

Para Le Goff (2003, p.422) “[...] o estudo da memória social é um dos meios fundamentais de abordar os problemas do tempo e da história, relativamente aos quais a memória está ora em retraimento, ora em transbordamento". Para o autor, a memória está sempre relacionada aos acontecimentos da história e, também, do tempo que rege a história.

Dessa forma, é que a memória - e suas várias possibilidades de guardar o passado - passa a ser um saber constituído de vários povos. Saber criado e socialmente construído. Quando se reconhece o papel dos sujeitos no processo cumulativo de transformação, a mensagem (TEIXEIRA COELHO NETTO, 2003) socialmente transmitida ganha status de memória (SHIKIDA; MOURA, 2007).

Para a presente pesquisa, optou-se por posicionar o estudo a respeito das abordagens individual, coletiva e social da memória, focando os contextos organizacional e institucional. Autores como Henri Bérgson, Maurice Halbwachs, Michel Pollak, Pierre Nora, Vera Dodebei, Icléia Thiesen Costa, Eliane Oliveira entre outros, foram estudados, 
como base para a construção do referencial teórico, relativos à memória como construção individual, coletiva e social.

\section{Memória e suas diferentes abordagens}

Lieury (1997), em seus estudos a respeito do cérebro, defende que este apresenta uma complexidade tão grande, que não pode ser compreendido por pesquisadores pertencentes a somente uma especialidade, mas sim, deve envolver diferentes disciplinas, abrangendo técnicas refinadas e de última geração. Aqui se inserem as Neurociências, sendo que a Psicologia faz parte desta especialidade, propondo modelos de funcionamento cerebrais, e psicológicos.

O mesmo autor descreve a estrutura cerebral como tendo três grandes estruturas especializadas no processamento das informações: "o tálamo é de certa forma o computador da percepção, os corpos estriados organizam e comandam os movimentos com o cerebelo, ao passo que o hipotálamo conduz nossa vida vegetativa" (LIEURY, 1997, p.20, grifo nosso).

O objetivo do estudo em tela não é aprofundar neste assunto, mas sim apresentar a complexidade do funcionamento cerebral humano. Dessa forma, com a existência de tal estrutura, na qual estão presentes o tálamo, os corpos estriados e o hipotálamo, a memória se divide em duas: declarativa e procedimental. A primeira está voltada à memória no sentido corrente do termo, possibilitando a rememoração e o reconhecimento de palavras, imagens etc., estando presente aqui, o hipotálamo. A segunda é a parte inconsciente, que permite as aprendizagens perceptivas e motoras, que dão sustentação aos nossos automatismos, como andar e dirigir. Neste caso, é imprescindível a presença dos corpos estriados (LIEURY, 1997, p.29). 
QUADRO 1: Tipos de Memória

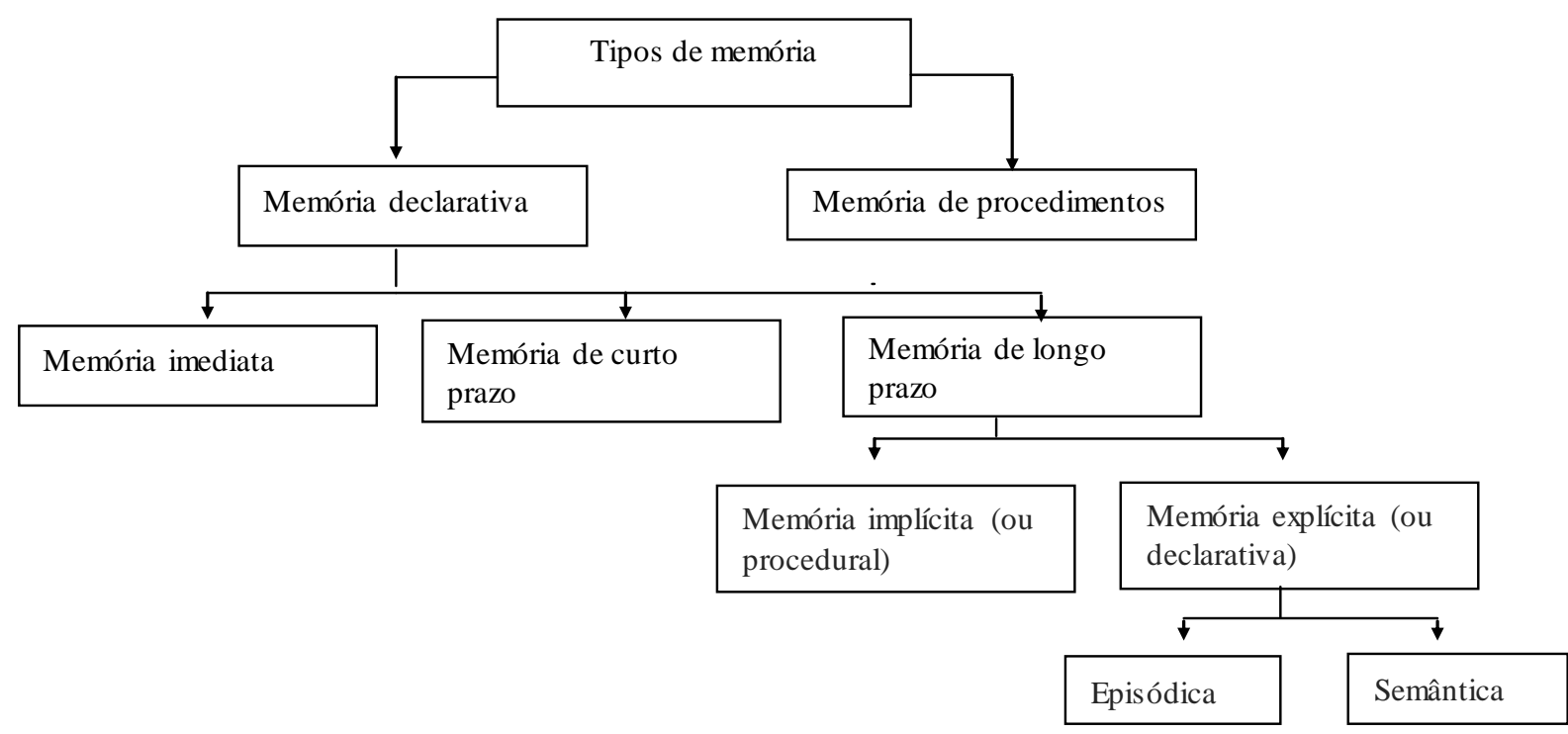

FONTE: adaptado de Pinto, 2001.

De acordo com Pinto (2001), o homem possui dois tipos de memória: declarativa e de procedimentos. O primeiro tipo, a memória declarativa, está relacionado à capacidade de verbalizar um fato, apresentando três formas: Memória imediata, que dura de frações a poucos segundos; Memória de curto prazo, sendo o sistema responsável pelo processamento e permanência temporária da informação para efeitos de conclusão das tarefas em curso; é um sistema limitado de retenção e armazenamento temporário de informação; e a Memória de longo prazo, que é o sistema que armazena a informação e conhecimento durante longos períodos de tempo. A memória de longo prazo se divide em: Memória implícita (ou procedural) - a que se dá sem o processamento consciente; compreende a memória de procedimentos, hábitos e habilidades; e a Memória explícita (ou declarativa) - aquela que requer o processamento consciente e que necessita de lembrança prévia do aprendizado adquirido; é toda aquela memória que podemos 
lembrar, através de uma evocação. É a memória para fatos, eventos e conhecimentos. Este tipo de memória se divide em: episódica, que é a memória de fatos sequenciados, com referência temporal; e semântica que envolve informações atemporais. O segundo tipo, a Memória de procedimentos, está relacionado à capacidade de reter e processar informações que não podem ser verbalizadas.

Neste momento, se faz uma importante distinção: a memória declarativa está relacionada à parte consciente do homem, quando ele atua de forma pensada; a memória procedimental, à parte inconsciente, quando a atuação é realizada de forma automática, ou seja, a aprendizagem já ocorreu, e o indivíduo não precisará pensar muito para realizar uma ação.

Em relação aos estudos tendo como foco o sujeito, o psicólogo Carl Gustav Jung, defende que a memória dispõe de espaços que possibilitam a construção de discursos e saberes, além da constituição de histórias, chamado de inconsciente coletivo, isto é, arquétipos que são construídos de forma coletiva, tendo como base representações simbólicas comuns aos indivíduos, e que são constituídos ao longo do tempo. Desta forma, os arquétipos se manifestando por meio do inconsciente coletivo, e o comportamento individual, em relação ao grupo ao qual o indivíduo pertence, apresentam coerência e proximidade (SHIKIDA, 2005, p.48).

Jung (1991), em sua teoria a respeito da estrutura psíquica do homem, chama de 'arquétipos' as formas mentais, sendo que há uma tendência instintiva na forma de nos comportarmos, bem como não pertencem somente a um indivíduo, mas coletivamente ao ser humano, isto é, são formas primitivas e inatas, e que representam uma herança do espírito humano. Ele defende que a mente humana é um produto que sofre interferências da história humana. Uma história que não é a cultural, mas referente ao desenvolvimento biológico e inconsciente do homem, desde os períodos mais remotos da existência humana.

De acordo com Shikida (2005, p.48) “[...] existe então uma certa coerência que se manifesta nas condutas individuais com relação a seu grupo. É o espaço histórico, de trocas coletivas propícias para a construção social do saber”. 
Nessa perspectiva, uma memória hereditária traz consigo uma estrutura preestabelecida de forma à priori, com seus conteúdos arquetípicos (o que não é defendido na Teoria Piagetiana); e outra que é adquirida por meio das relações que o homem estabelecerá com seu meio.

$\mathrm{Na}$ área da Educação, na qual a aprendizagem é o foco, Pinto (2001) defende que esta é idealizada quanto à aquisição de novas informações, e à sua integração no conjunto de conhecimentos existentes. Nesta perspectiva, aprender não se limitaria apenas à aquisição de novas informações, mas também a aprofundar e reorganizar nossa base de conhecimentos existentes. Desta forma, a aprendizagem não seria considerada como um processo independente dos outros processos mentais, como os de atenção, percepção, memória e raciocínio, e sim como fazendo parte de todos os processos cognitivos que possuímos.

Foster (2011, p.12) relata que "Teóricos contemporâneos passaram a ver a memória como um processo seletivo e interpretativo. Em outras palavras, ela é mais do que simples armazenamento passivo de informações. Além disso, podemos selecionar, interpretar e integrar uma coisa e outra - para fazer uso do que aprendemos e lembramos".

Dessa forma, à memória é “[...] resguardado o lugar do lembrar, construir, desconstruir e compor. Trabalho de elaboração, reflexão, localização. Lembrar não é reviver, é antes de tudo, refazer caminhos e trajetórias. É organizar e ordenar o tempo, bem como situar o passado em uma cronologia que é única" (SHIKIDA, 2005, p.44). A memória é vista como uma estrutura complexa que, faz do homem o único ser capaz de construir, desconstruir, reconstruir, compor e recompor lembranças e conteúdos internalizados, modificando-os e gerando outros conteúdos, informação e conhecimento que podem ser aproveitados por seus pares.

Percebe-se que o homem, durante a sua evolução e, consequentemente, da sociedade, tem desenvolvido técnicas que o ajudam a se comunicar de forma consistente, além de possibilitar diferentes formas de registro do seu conhecimento. Inicialmente, transmitia-se a informação de forma oral; porém, com o passar do tempo, diferentes formas de escrita foram sendo criadas, conforme sua evolução e a sociedade a qual ele 
pertencia. No decorrer da história humana, a informação foi registrada em pedras, mármores, na argila, no papiro, no pergaminho, no papel, e atualmente no formato eletrônico/digital.

Em relação à escrita, é considerada como desempenhando um papel imprescindível na preservação da memória coletiva, visto que é capaz de possibilitar o registro do passado; porém, também é capaz de silenciar o que poderia ser dito na tradição oral. Além disso, a escrita só ocorreria depois de uma reflexão a respeito do que realmente merece ser lembrado, além do que deve ser esquecido (HOLANDA, 2011). Ou seja, com o surgimento da escrita, o homem pôde escolher e selecionar o conteúdo/saber de uma determinada comunidade, que seria relembrado ou esquecido.

Outro fator importante ligado à escrita é a alfabetização, que influi na forma como se articula o conhecimento. Uma vez que se textualiza, tende a evoluir de um modo textual característico, que tem pouca conexão com a forma em que evolui o conhecimento no pensamento e na fala (FENTRESS; WICKHAM, 2003, p.29).

Porém, Lévy (1993, p.91-92) alerta que as chamadas tecnologias intelectuais, como a escrita, seriam consideradas como auxiliares cognitivos dos processos controlados, sendo aqueles que envolvem a atenção consciente, e que dispõem de poucos recursos no sistema cognitivo humano. Destarte, funcionariam como "paliativo em relação a certas fraquezas dos processos automáticos como as heurísticas de raciocínio e os mecanismos esquematizantes da memória de longo prazo".

Nessa perspectiva, o fato da memória humana não conseguir registrar com exatidão toda informação e conhecimento constituídos, o uso da escrita possibilita o registro de parte desse conteúdo, sendo que outra parte será perdida, esquecida. Deixará de fazer parte da memória daquele indivíduo ou sociedade. Porém, a memória aparece não somente como um mecanismo que copia informação e a guarda em nossa cabeça; ela também possibilita a recuperação dessa informação e a combina para formar novos pensamentos (FENTRESS; WICKHAM, 2003, p.34). Este processo de combinação e recuperação de informações somente o ser humano possui, e que foi descrito anteriormente, por Lieury, quando apresenta a estrutura cerebral do homem. 
Assim sendo, os terminais sensoriais vão lhe possibilitar tomar contato com sensações que lhe transmitirão informações, captadas pelo meio; e princípios e regras que permitem continuamente (como defende Piaget no seu princípio de continuidade funcional) a organização do seu conhecimento, por meio de suas estruturas cognitivas (estabelecidas biologicamente).

Muitas das dificuldades clássicas dos tratamentos filosóficos e psicológicos da memória surgem da intenção de conciliar os 2 aspectos acima citados, ou seja, a memória como um mecanismo de recuperação de informação e também de combinação, para formar novas ideias.

Dessa forma, Lévy (1993) defende que a memória humana não pode ser comparada a um equipamento de armazenamento e recuperação fiel de informações. Além disso, a Psicologia Cognitiva contemporânea defende que não temos apenas uma memória, e sim várias, com sua estrutura funcionando de forma distinta. Ou seja, a memória de curto prazo (ou memória de trabalho) estaria voltada à atenção; e a memória de longo prazo estaria relacionada a uma única e imensa rede associativa, no qual os elementos diferenciariam em relação ao conteúdo informacional, e também quanto à força e número das associações por eles realizadas.

Para este autor, a memória humana possibilita o armazenamento e recuperação de informações, porém, não de forma exata, assim como não pode ser comparada a um sistema baseado em tecnologia, visto que podem ocorrer algumas falhas neste processo de armazenamento e recuperação, pelo fato de o cérebro humano ter seu funcionamento de forma complexa. Além disso, o homem possui diferentes formas de memória: auditiva, visual, sensorial, emocional, etc., estudadas pela Psicologia e pela Neurociência.

Fentress e Wickham (2003) defendem que a memória está dividida em dois segmentos: uma parte objetiva que serve como repositório de fatos, podendo ser guardados em lugares externos, ou seja, podem ser externalizados e registrados; e uma parte subjetiva, que inclui informações e sentimentos que fazem parte integral de todos nós, localizados internamente. Os autores defendem que a parte objetiva da memória é 
passiva, visto que guarda apenas conteúdo/informação. Já a parte subjetiva é mais ativa, pois passa pelo processo de experimentação e análise de consciência.

O que se observa com o contexto defendido pelos autores, é que a parte objetiva da memória depende da parte subjetiva e vice-versa, visto que o processo subjetivo gera o conhecimento que será registrado pela parte objetiva da memória.

A memória objetiva é o melhor veículo para a transmissão da informação; é o aspecto de nossa memória que os demais podem contar com maior facilidade. Porém, essa distinção nada tem a ver com sua estrutura, visto que é um fato social. Assim posto, o que surge na articulação não é a parte objetiva da memória, senão seu aspecto social (FENTRESS; WICKHAM, 2003).

Os mesmos autores também defendem a memória como fato social, porém apenas em parte, porquanto parte de nossas recordações parece ser mais íntima e pessoal que outras, porém esta distinção entre memória pessoal e social é relativa, uma vez que nossas recordações são um misto, possuindo tanto aspectos sociais quanto subjetivos (FENTRESS; WICKHAM, 2003, p.25). Aqui, a memória é defendida como constituída socialmente em parte, porquanto responsabiliza o sujeito cognoscente por sua construção na outra parte, por meio de suas experiências, percepções e sensações percebidas e registradas individualmente.

Diante do exposto, pode-se concluir que os autores consideram a memória como uma estrutura subjetiva. Mas, ao mesmo tempo, ela está estruturada pela linguagem, aprendizagem e observação, ideias coletivas e experiências compartilhadas com outros indivíduos, os quais se convertem em social. Apesar de seu caráter subjetivo, isso não significa que não pode gerar informação objetiva (FENTRESS; WICKHAM, 2003), que é o veículo transmissor da informação.

Para Lévy (1993, p.77), a sociedade oral primária, aquela que remete ao papel da palavra, antes da adoção da escrita, “[...] quase todo o edifício cultural está fundado sobre as lembranças dos indivíduos. A inteligência, nestas sociedades, encontra-se muitas vezes identificada com a memória, sobretudo a auditiva”. Dessa forma, nesse período o conhecimento era relembrado e repassado às novas gerações na forma de ritos, rituais, 
festividades, ou seja, por meio da realização de festividades de datas comemorativas.

Corroborando esta ideia, Fischer (2006), relata que, ao final do Século IV a.C., com o surgimento da escrita, há uma modificação em relação à transmissão do conhecimento social, que passou do oral para a forma escrita, registrada. A escrita passou a documentar, a preservar e, consequentemente, a validar o conhecimento gerado naquela época, tornando-se possível ser localizado e disseminado.

Dessa forma, os acontecimentos poderiam ser registrados em algum tipo de suporte, tirando da memória humana a função exclusiva de reter e preservar as informações. Diante desse contexto, a memória sofre um processo de afastamento do sujeito ou da comunidade, e torna-se objetiva, morta, impessoal, causando a separação do conhecimento, da identidade pessoal e coletiva; o saber se torna disponível, estocável, consultável, comparável, transformando-se em um objeto possível de análise e exame, e não somente considerado como útil no dia a dia (MONTEIRO; CARELLI; PICKLER, 2008). Esse processo trouxe grandes transformações na forma em que a informação era retida e transmitida: o indivíduo perde seu poder de ser o único a reter e transmitir o saber; as informações passam a ter um cunho mais coletivo do que individual, visto que mais pessoas teriam acesso ao registro do conteúdo; o saber de toda uma comunidade passa a ser passível de ser analisado e modificado; porém, sem o devido cuidado quanto a sua preservação, também aumenta a possibilidade de ser perdido.

O desenvolvimento científico e filosófico do Século XVII se associou à facilidade de empregar as propriedades da linguagem para a construção de sistemas de classificação e metarreferência cada vez mais abstratos. Além disso, a expansão da imprensa causou um desenvolvimento tecnológico tão importante quanto o da escrita. A representação visual do conhecimento, primeiro nos textos escritos e depois nos livros impressos, ocasionou o descobrimento da estrutura formal, sintática e lógica do conhecimento (FENTRESS; WICKHAM, 2003), ou seja, o desenvolvimento científico e tecnológico, juntamente com o surgimento e expansão da imprensa causaram grandes transformações no mundo. $O$ conhecimento gerado naquela época, sendo registrado e preservado, passou a ser mais difundido gerando mais informação e conhecimento como jamais havia ocorrido até aquela época. 
Dessa forma, Le Goff (2003, grifo meu) explica que o aparecimento da escrita trouxe uma profunda transformação relativa à formação da memória coletiva, proporcionando um processo duplo, isto é, o desenvolvimento de duas formas de memória: a comemoração, ou seja, celebração realizada por meio da construção de um monumento comemorativo relativo a um acontecimento considerado memorável; e documento, registrado em um suporte destinado à escrita.

Para Le Goff, o termo 'monumento' possui características relacionadas “[...] ao poder de perpetuação, voluntária ou involuntária, das sociedades históricas (é um legado à memória coletiva) e o reenviar a testemunhos que só numa parcela mínima são testemunhos escritos" (LE GOFF, 2003, p.526).

Por outro lado, o termo 'documento', segundo o mesmo autor, provém do latim documentum, que é derivado de docere, ou seja, relativo ao ato de 'ensinar'. Na história, o termo evoluiu para o significado de 'prova', sendo vastamente usado pelo e no vocabulário legislativo. Dessa forma, mesmo que o documento tenha sido considerado como um fundamento histórico, por decisão do historiador, para a escola histórica positivista do fim do Século XIX e início do Século XX, parece apresentar-se por si mesmo como prova histórica. Portanto, um documento mediante sua objetividade, opõe-se à intencionalidade do monumento, além de afirmar-se fundamentalmente como um testemunho escrito (LE GOFF, 2003).

Nessa perspectiva, a da memória coletiva construída socialmente, a construção de monumentos, quase sempre está ligada à celebração de algo que deve ou que se deseja ser memorável (mas nem sempre esta intenção está presente); já o documento escrito é visto como forma de registro dos acontecimentos de determinada sociedade. Em relação aos monumentos, Le Goff questiona os reais motivos de se construí-los, visto que nem sempre a sociedade os vê/sente como uma celebração de um acontecimento memorável, ou seja, daquilo que deve ser realmente lembrado e comemorado, mas sim de acordo com o desejo e vontade de um determinado governante, como temos visto no decorrer da nossa história.

Dodebei (2010, p.71) relata que “[...] a memória compreendida sob a dimensão 
cultural pode abarcar fronteiras de outras disciplinas que têm o passado como material de estudo, como a História, a Arqueologia, a Ciência da Informação". Áreas como a Psicologia e a Neurociência teriam como foco "[...] o funcionamento da memória e sua plasticidade" e de como o indivíduo se comporta frente às lembranças e experiências pelas quais passa no período de sua existência. Contudo, como defende Rossi (2010), o discurso a respeito do tema memória é muito antigo, não se identificando e não se esgotando nem com o tema das artes da memória, nem com os problemas tratados pela área das Neurociências. Para o autor, o tema é extremamente amplo, aprofundando suas raízes no receio primeiro, que acompanha a história de espécie humana, assim como a vida dos indivíduos, desde sua infância, até seus últimos dias.

Para Le Goff (2003, p.427, grifo meu), a memória coletiva, nas sociedades sem escrita, dispõe-se em torno de três importantes fatos: "a idade coletiva do grupo, que se funda em certos mitos, mais precisamente em mitos de origem; o prestígio das famílias dominantes, que se exprime pelas genealogias; e o saber técnico, que se transmite por fórmulas práticas fortemente ligadas à magia religiosa”. Os saberes gerados pelas sociedades sem escrita dependiam das ações e disponibilidade das famílias que dominavam certas comunidades, assim como a idade grupal e o saber técnico. Estes dois últimos fatos estavam relacionados com passagens, ritos, rituais e mitos, pertencentes especificamente a cada sociedade tribal.

Dodebei (2010), em seus estudos relativos à memória, verifica que “[...] é somente a partir do século XX que o mundo é visto como um espaço informacional e memorial, em que os aspectos materiais e imateriais dos objetos criados pelas sociedades entram em disputa". É nesse momento, que a produção cultural e social começa a ter valor de memória, resgatados e ligados à sociedade que a produz.

Dessa forma, Crippa (2010) considera que a memória permite o resgate de algo pertencente ao passado, comparando-os com os dados do presente, proporcionando a preservação de determinadas informações, essenciais para a experiência individual e o conhecimento de natureza científica, filosófica ou técnica. A memória é considerada o único instrumento por meio do qual, ideias e palavras podem ser reunidas, fugindo, assim, ao império do imediato: imprime as direções do tempo e permite uma 
continuidade social. Sem ela, desapareceriam os elos sociais, assim como a própria noção de sociedade, as identidades individuais e coletivas, a possibilidade da construção do conhecimento, ou seja, pode ser considerada uma ferramenta para a construção de uma determinada sociedade, assim como de transmissão cultural.

Nesse contexto, a autora acima citada defende que as diversas formas de conhecimento existentes são fruto das formas de organização da memória de um conhecimento de uma época específica, que é ligada ao desenvolvimento pelo qual o pensamento científico passou e tem passado, assim como referente aos objetivos das instituições públicas da época (CRIPPA, 2010).

Além disso, para Santos (2003), nós somos formados pela memória que temos; ela não é só pensamento, imaginação e construção social. Nossa memória é formada por uma determinada experiência de vida capaz de transformar outras experiências, quando em contato com resíduos deixados anteriormente. A memória vai além da mente humana, do corpo, do aparelho sensitivo e motor, do tempo físico, sendo objetivada em representações, rituais, textos e comemorações.

Esta visão defendida por Santos corrobora com o fato de que várias áreas do conhecimento humano estudam a memória, cada qual com sua percepção e especificidades.

A autora ainda relata que em relação às reflexões filosóficas, a memória foi associada, por muitos anos, à noção de tempo. Porém, não se refere apenas ao passado. Como ela faz parte da existência humana, ultrapassa o escopo da reflexão humana, assim como a noção que o homem tem de passado e presente. Desta forma, fazendo parte do cosmos, não pode ter uma única definição (SANTOS, 2003).

Podemos considerar que a memória está intimamente ligada ao futuro, pois é a partir do que temos internalizado como sujeitos cognoscentes, que nos estruturamos como indivíduos sociais e construímos nosso presente, e consequentemente, influímos em nosso futuro, isto é, não existe futuro sem passado.

A distinção passado/presente que aqui nos ocupa é a que existe na consciência coletiva, em especial na consciência social histórica. Mas torna-se necessário, antes de 
qualquer coisa, chamar a atenção para a pertinência desta posição e evocar o par passado/presente sob outras perspectivas, que ultrapassam as da memória coletiva e da história. De fato, a realidade da percepção e divisão do tempo em função de um antes e um depois não se limita, em nível individual/coletivo à oposição do presente/passado, sendo necessário acrescentar uma terceira dimensão, o futuro (LE GOFF, 2003).

Como defende Bergson (2011), um instante não substitui outro instante, pois desta forma, haveria somente o presente, não existindo um prolongamento do passado no presente, não existiria evolução, nem uma duração concreta. Duração esta que apresenta um progresso que é uma continuidade do passado, que o faz aumentar, conforme avança. Assim, pelo fato do passado crescer continuamente, também se preserva indefinidamente. Além disso, na visão de Bergson, a memória não serviria somente para classificar recordações em uma gaveta, nem de inscrevê-las em um registro. Esta seria uma percepção muito simplista para um mecanismo tão complexo quanto ela é.

Bergson explica que os acontecimentos não se sobrepõem, o que faria existir somente o presente. Desta forma, relacionando a memória ao tempo, mais especificamente ao passado, ele chama a atenção para o fato de este crescer continuamente, por meio do registro dos acontecimentos e experiências pelas quais o homem passa, que são preservados na nossa memória. Memória esta que, por meio de sua estrutura complexa, além de registrar e classificar acontecimentos e recordações, também é capaz de fazer ligações, religações, relacionamentos entre lembranças, de diferentes formas.

O autor ainda defende que, neste processo, tudo poderia acontecer como se nossas lembranças se repetissem indefinidamente nessas inúmeras reduções possíveis por meio de nossas vivências passadas. Assim, estas lembranças poderiam adquirir diferentes formas: mais banal quando a memória se estreita, e mais pessoal quando se dilata. Desta forma, poderiam ocorrer diferentes e ilimitadas "sistematizações" (BERGSON, 2010), ou seja, combinações diferentes relativas a um mesmo acontecimento, ou na junção de diversos acontecimentos. Estas "sistematizações" apresentadas pelo autor nos possibilitariam realizar diferentes combinações, relativas às experiências vivenciadas pelo sujeito. 
Outra forma de estudar o tema "memória” é sob o foco da Filosofia. Rossi (2010, p.15), explica que, na Filosofia, assim como no “[...] modo de pensar comum, [...] [a memória] parece referir-se a uma persistência, a uma realidade de alguma forma intacta e contínua; a reminiscência [...] pelo contrário, remete à capacidade de recuperar algo que se possuía antes e que foi esquecido".

Nesta perspectiva, a memória é considerada como a informação registrada e guardada, internamente, exatamente como o indivíduo havia percebido; e o seu oposto, a reminiscência, como algo a ser relembrado, do que já foi esquecido, por meio de uma 'rememoração'.

Em relação à questão da 'rememoração', Ricoeur (2007) explica que rememorar é quando há o retorno de um conteúdo/lembrança à consciência. Conteúdo este despertado por meio de um acontecimento que é reconhecido como tendo ocorrido anteriormente ao momento em que a consciência declara tê-lo sentido, percebido ou sabido. Por outro lado, a memorização, é constituída de formas de aprender, que compreendem saberes e habilidades, possibilitando que estes sejam fixados, permanecendo disponíveis para uso. Além disso, percebemos aqui, a presença de dois termos a serem estudados: memória e reminiscência.

Em relação aos dois termos acima citados, memória e reminiscência, Bergson (2010) defende que o mecanismo cerebral humano é capaz de recalcar quase totalmente o passado no inconsciente, e só trazer à consciência o conteúdo que ajude na preparação de uma ação, possibilitando o esclarecimento/resolução de uma situação presente.

Para este autor, a memória está ligada ao consciente e ao presente servindo para solucionar os problemas atuais; e a reminiscência está ligada ao inconsciente, aquilo que deve ser esquecido ou recalcado. Essa visão é próxima ao que defende a Psicologia, visto que trabalha com o consciente e com o inconsciente. $O$ primeiro se referindo ao estado de alerta do indivíduo; e o segundo, às lembranças das quais ele quer ou precisa se esquecer, como um mecanismo de defesa, para sua própria sobrevivência.

Em relação ao esquecimento, outra face da memória estudada por pesquisadores como Ricoeur (2007) e Holanda (2011, p.131), é percebida como um “[...] lapso ou 
manipulação da memória, tanto individual quanto social, tanto natural quanto artificial, sendo uma questão vital para a memória humana para que o indivíduo não se sobrecarregue de informações, tão natural quanto lembrar, é esquecer-se”.

Este é considerado um mecanismo natural do funcionamento cerebral, defendidos pelas áreas da Neurociência e da Psicologia, visto que o cérebro faz uma seleção do quê deve ser guardado, e do quê deve ser esquecido. Não conseguimos guardar/registrar tudo que aprendemos; caso contrário o cérebro entraria em 'pane'. Além disso, como defende a Psicologia, o indivíduo possui alguns esquemas mentais, em que 'registra' na consciência o que percebe que deve ser lembrado rapidamente para uso diário e, por outro lado, 'registra' no inconsciente conteúdos que ele percebe que devam ser esquecidos, como um mecanismo de defesa.

Como defende Nora (1993, p.15) “O que nós chamamos de memória é, de fato, a constituição gigantesca e vertiginosa do estoque material daquilo que nos é impossível lembrar, repertório insondável daquilo que poderíamos ter necessidade de nos lembrar”.

Na área da Ciência da Informação (Cl), Oliveira (2010) realizou um estudo relativo à conceituação do termo memória, por meio da análise da produção científica nesta área. Utilizando-se das categorias "Memória Humana", “Memória Artificial” e "Memória Social", ela observou que a Memória Humana está relacionada aos estudos da memória de longo prazo, memória de curto prazo e memória dos idosos; a Memória Artificial, à memória dos computadores; e a Memória Social, aos estudos da preservação da memória, memória de leituras, memória na escola, instituições de memória, centros de memória, arquivos de memória, lugares de memória, entre outros.

Ou seja, para Dodebei e Gouveia (2008), os estudos atuais relativos à memória envolvem uma perspectiva transdisciplinar, permitindo às diferentes áreas do conhecimento dialogar entre si. Isso acontece talvez pelo fato das primeiras investigações ocorrerem em torno da possibilidade de lembrar e esquecer, temas estudados por diferentes áreas do conhecimento. No início do Século XIX, a Psicologia começava a estudar, de forma sistemática, a memória humana e sua capacidade individual de recuperação de informações, que posteriormente se misturou aos estudos 
dos processos neurobiológicos, também voltados a este tema, porém com outra visão.

Em relação ao termo Memória Institucional (MI), temos os estudos de Icléia Thiesen Costa (1997), principal pesquisadora que trabalha com esta temática, definindo memória como um elemento primordial no funcionamento das instituições, porquanto é por meio da memória que as instituições se reproduzem no seio da sociedade, retendo somente as informações que interessem ao seu funcionamento. A autora, que estuda a memória no ambiente das instituições, defende que estas são "[...] integradoras e formalizadoras de práticas e comportamentos, com a função de fixar enunciados para, em seguida, reproduzi-los" (COSTA, 1997, p.144).

A autora defende que, de instituição para instituição, há um processo seletivo que irá desenvolver suas regras, de acordo com suas características. As informações consideradas relevantes para a recuperação da MI devem ser buscadas, além de materiais e fontes internas à instituição, também no seu entorno, estando em permanente elaboração, visto que é formada em função do tempo (COSTA, 1997; THIESEN, 2013).

Além disso, considera o conceito de memória, dentro de toda a sua complexidade, também é uma faculdade do espírito, que é base de toda a criação. Desta forma, é uma invenção do ser humano, que retém as informações recebidas, passando por um filtro individual, sendo organizadas e recriadas no presente, inserido em um processo dinâmico (THIESEN, 2013).

Para Pollak (1989, p.9),

a memória, essa operação coletiva dos acontecimentos e das interpretações do passado que se quer salvaguardar, se integra [...] em tentativas mais ou menos conscientes de definir e de reforçar sentimentos de pertencimento e fronteiras sociais entre coletividades de tamanhos diferentes [...]. A referência ao passado serve para manter a coesão dos grupos e das instituições que compõem uma sociedade, para definir seu lugar respectivo, sua complementaridade, mas também as oposições irredutíveis.

Para Costa (1997, p.146), “[...] nós somos e fazemos as instituições. E a memória institucional é o reflexo dessa trajetória, não como mimesis, mas um cristal com suas 
múltiplas e infinitas facetas. É também uma memória histórica, efeito dos condicionamentos e das formações históricas".

Nesse contexto, as informações podem ser buscadas tanto interna quanto externamente às instituições. Além disso, a MI está em permanente elaboração e evolução, visto que é resultante da função do tempo, ou seja, a MI engloba a instituição como um todo, sendo formada com o passar do tempo. A autora também defende que os indivíduos é que fazem a memória das instituições, sendo ela o reflexo dessa trajetória social e histórica. Porém, Costa (1997) deixa claro, em sua pesquisa de doutorado, que o conceito de MI não foi definido de modo sistemático.

Barbosa (2010), para uma compreensão do conceito de $\mathrm{MI}$, recorre à Bergson (2006), Halbwachs (2006) e Pollak (1992). Ela defende que a MI consistiria em uma reconstrução do passado, pois somente podemos voltar a ele, por meio da memória. A estruturação da memória de uma organização deve sofrer um processo de escolha e de seleção daquilo que realmente é útil e importante para a organização, sendo considerada como uma narrativa entre o contexto organizacional, e aquilo que é relevante para cada indivíduo, para o grupo e também para a própria organização.

Na visão da mesma autora, a constituição da MI seria por meio da (re)construção de fatos e acontecimentos que seriam considerados significativos em relação à trajetória e experiências pelas quais a organização passou. Esse conteúdo passaria por um processo de seleção e organização, com objetivo de construção da identidade da organização (BARBOSA, 2010).

Nesse contexto, o que precisa ser analisado e avaliado, em relação à produção de informação, é o que realmente é relevante e importante para a organização guardar, visto que muito conteúdo é produzido diariamente, e nem todo conteúdo é relevante. Esse processo precisa ser pensado como um processo de estruturação da identidade organizacional.

Ainda em relação à constituição do termo “Memória Institucional”, Paulo Nassar, profissional da área de Relações Públicas, considera que, para se constituir a memória, é necessário utilizar da narrativa individual, social ou organizacional, que 
consequentemente são estruturadas a partir das memórias individuais, sociais ou organizacionais. Além disso, esta construção está alicerçada, e tendo como base, o que é relevante para cada indivíduo, grupo ou organização (NASSAR, 2008).

Na visão do autor, os pilares da memória seriam: a cultura, os comportamentos, os símbolos, a identidade e a comunicação. Além disso, a memória seria seletiva, conforme também defendido por Barbosa (2010), visto que as experiências, tanto as positivas quanto as negativas, seriam selecionadas de acordo com a organização, os gestores, empregados, seus produtos e serviços (NASSAR, 2008). As experiências positivas serviriam como conteúdo para ser (re)usado e difundido dentro da organização; as experiências negativas serviriam como exemplo do quê não deveria ocorrer novamente. Porém, todas teriam como objetivo a aprendizagem.

Nos estudos da área de Comunicação Empresarial, o termo MI é utilizado como sinônimo de Memória Empresarial, constituindo-se numa área de atuação específica e importante no universo empresarial, ainda que se assista a várias distorções de seus princípios fundamentais, em particular no Brasil. Essas distorções se relacionam a projetos que, apesar de se autointitularem "históricos", não se valem da metodologia de análise da ciência, seja em relação à multiplicidade de fontes de pesquisa, seja ao compromisso com sua legitimidade (TOTINI; GAGETE, 2004).

Quando se trata da história empresarial, é importante verificar o que é "selecionado no campo da memória pelos gestores que formam a direção da organização. [...] em que espaços, momentos e condições são feitas essas seleções [...] destacar quais são os fatos e os personagens esquecidos no âmbito da história empresarial" (NASSAR, 2008, p.115).

No Brasil, o estudo da memória empresarial partiu da iniciativa de acadêmicos, a partir da década de 1960, interessados na reflexão sobre a estrutura e a evolução industrial brasileira, buscando compreender a relação entre os aspectos econômicos, a ideologia, e a estrutura paternalista dessas empresas (TOTINI; GAGETE, 2004).

As autoras acima citadas (2004) ainda relatam que cada vez mais empresas e instituições têm se aproveitado de projetos de memória empresarial, utilizando-os como 
ferramenta de gestão estratégica, tanto no que se refere ao autoconhecimento imprescindível às tomadas de decisão quanto ao tempo presente, quanto ao planejamento do futuro, assim como na construção de políticas de relacionamento com seus stakeholders.

O que se observa é que a MI, para a área de Relações Públicas, está voltada à estruturação da identidade da organização, assim como está ligada à comunicação organizacional.

Barbosa (2010, p.42) também defende que a MI pode ser compreendida como uma possibilidade de comunicação organizacional. Nesse caso, além da questão da construção da identidade da organização, também para criar relacionamentos de valor entre os públicos estratégicos, de forma a garantir o processo de negociação, assim como o de fortalecimento da reputação organizacional. "Mas, embora essa identidade seja volátil e mutável em razão da complexidade do ambiente organizacional, é ela que pode propiciar o senso de pertencimento e a partilha de significados entre os sujeitos e a instituição".

Nesse sentido a MI pode ser considerada como uma possibilidade de (re) ligação do indivíduo à organização, podendo se reconhecer como um elemento participante de sua trajetória (da organização). Além disso, pode contribuir para o reconhecimento dos indivíduos em relação a uma identidade forte, e um sentimento de pertencimento, sentimento este que representa algo que distingue e consolida o relacionamento do público, com a organização (BARBOSA, 2010).

A autora considera a MI como uma possibilidade do sujeito se sentir pertencente à organização, visto que participou da trajetória da identidade daquela organização da qual faz ou fez parte em algum momento da sua vida.

Quanto à área de Informática e Tecnologia, Le Goff (2003) em seus textos a respeito da história e memória, e em suas análises do contexto de surgimento da Informática, já defendia a existência da 'memória eletrônica' agindo somente sobre os programas de base tecnológica desenvolvidos pelo homem. Além disso, a memória humana mantém um setor não 'informatizável', ou seja, difícil de ser alcançado e 
explicitado seu conteúdo. Isto é, a memória eletrônica seria considerada tão somente um auxiliar da memória e do espírito humano, assim como outros tipos de memórias automáticas.

No ambiente organizacional, Macedo (2003) defende que a realização das atividades organizacionais diárias resulta na produção de informação e conhecimento, além de inúmeros documentos que se espalham pelos diversos departamentos na organização. Dessa forma, o conhecimento que é produzido e organizado institucionalmente forma uma base de conhecimentos fundamental para a tomada de decisões no ambiente organizacional, que se reflete na forma de ações políticoeconômicas e administrativas. A esta base de conhecimentos, denominamos de Memória Organizacional (MO).

Corroborando com a mesma ideia, Spiller e Pontes (2007, p.99) explicam que “[...] as experiências pelas quais passa uma organização são acumuladas, ao longo dos anos, nas suas pessoas, cultura, processos e em seus documentos, e esse conjunto de conhecimentos forma a sua memória”. Assim, a memória de uma organização envolve todo seu ambiente, perpassando por sua cultura organizacional, de recursos humanos, estrutura organizacional, estrutura tecnológica, e toda a documentação que ela produz mediante sua atuação.

Alguns desafios são encontrados no gerenciamento do conhecimento, e o primeiro deles é que, dentro da organização existe tanto conhecimento tácito quanto conhecimento explícito. Em algumas situações o conhecimento tácito pode ser externalizado e transformado em conhecimento explícito, mas em outras situações não. Caso o conhecimento se encontre em documentos, é importante preservar o contexto, o que torna o processo mais complexo ainda. Esse aspecto é de suma importância, de forma que o sistema seja concebido visando coletar e organizar sistematicamente as informações a partir de várias fontes, apoiando-se fortemente em métodos e técnicas da gestão do conhecimento (SASIETA; BEPPLER; PACHECO, 2011).

Siqueira (2005, p.125) argumenta que em relação ao termo MO, considera o uso de procedimentos que possibilitem “[...] localizar, representar, disponibilizar, medir e evoluir 
os conhecimentos estratégicos da corporação de maneira sistemática e organizada, [entendendo-se] que esse processo é viável, necessário e capaz de trazer resultados eficientes". A MO consistiria em uma estrutura de base tecnológica, permitindo que o conhecimento da empresa seja sistematicamente levantado, tratado, registrado e disseminado, possibilitando sua localização e preservação, visto que o conteúdo está organizado de forma lógica.

Segundo Simão (2010), o termo MO é utilizado em inglês, como: corporate memory ou organizational memory, ou seja, Memória Corporativa e Memória Organizacional são utilizadas como sinônimos. Para este autor, a Memória Organizacional deve “[...] permitir responder às principais questões que se faça sobre a organização, seu ambiente, seus processos e produtos".

Lehner e Maier (2000) confirmam, através de seus estudos, que existem várias expressões utilizadas como sinônimos para MO: base de conhecimento empresarial, memória de grupo, mente de grupo, memória coletiva, inteligência coletiva, inteligência corporativa, base de conhecimento compartilhado, repositório corporativo, banco de dados de know-how, portanto, diferentes termos compreendidos com o mesmo significado.

Destarte, percebe-se que existem várias definições para o termo $\mathrm{MO}$, visto que inicialmente foi estudada pela Sociologia, e depois reinterpretada de diversas maneiras. 0 autor defende que a MO é uma parte da memória coletiva, e esta evolui dos estudos realizados por Émile Durkheim, no final do Século XIX. Para Durkheim, a mente coletiva é composta de um conjunto de mentes individuais, que compartilham informações e conhecimentos, por meio da troca de símbolos. Dessa forma, a memória coletiva está relacionada aos processos sociais de articular e transmitir informações, levando a interpretações que são compartilhadas, e que foram armazenadas, estabelecidas como normas sociais e costumes. Essa formulação original possibilitou o surgimento da noção de memória como um sistema social particular, a organização (STEIN, 1995).

Diante de diferentes termos utilizados para MO, Almeida (2006, p.57) defende que "[...] o conceito de MO merece mais atenção, visto que fatos importantes da vida 
organizacional, inseridos nas teorias e práticas gerenciais: é essencial para o planejamento, para a comunicação, para a tomada de decisão e para o processamento da informação".

Segundo Almeida (2006), a memória pode ser considerada uma função que beneficia os seres humanos, pois permite a utilização de experiências passadas na solução de novos problemas; proporciona lembranças sobre experiências pessoais, possibilitando formas de antecipar eventos. Para tanto, ela se fundamenta em habilidades de aquisição, de armazenamento, de recuperação e de uso de informação.

No entanto, Santos (2003) alerta que a grande ameaça do mundo moderno é a perda da memória como aprendizado, inserida no mundo da informação. Com a substituição do operário de fábrica, o trabalho se reduziu a simples atos mecânicos e repetitivos, não sendo necessário o uso do aprendizado, acumulado por toda uma vida, para o desenvolvimento das atividades laborais. Além disso, a passagem da sociedade oral para a escrita faz com que parte da transmissão de conhecimento e valores entre as gerações sejam perdidas. Isso porque na sociedade oral havia toda a estruturação de rituais para a transmissão do conhecimento. Com o surgimento da escrita, a memória transmitida por textos, objetos, pedras, edifícios e máquinas, embora deem a impressão, não possibilitam a preservação total do passado, reproduzindo somente parte do que foi vivenciado.

\section{Metodologia}

A metodologia corresponde a um conjunto de procedimentos a serem utilizados na obtenção do conhecimento. É a aplicação do método, através de processos e técnicas, que garante a legitimidade do saber obtido. 
Do ponto de vista da sua natureza, é uma pesquisa básica, sendo aquela que objetiva gerar conhecimentos novos úteis para o avanço da ciência sem aplicação prática prevista.

Como metodologia de pesquisa, de cunho teórico, foi utilizada a pesquisa bibliográfica, que segundo Santos (2005), é feita com base em documentos já elaborados, tais como livros, dicionários, enciclopédias, periódicos, jornais e revistas, além de publicações como comunicação e artigos científicos, resenha e ensaios críticos. Oliveira (2007, p.69) defende que a principal finalidade da pesquisa bibliográfica é levar o “[...] pesquisador(a) a entrar em contato direto com obras, artigos ou documentos que tratem do tema em estudo".

Gil (2009, p.61) explica que o [...] levantamento bibliográfico preliminar pode ser entendido como um estudo exploratório, tendo como finalidade, proporcionar a familiaridade do aluno com a área de estudo no qual está interessado, bem como sua delimitação.

Para Santos (2005, p.92), a pesquisa bibliográfica "tem como instrumento essencial a habilidade de leitura [...] a capacidade de extrair informações a partir de textos escritos".

De acordo com Gil (2009, p.44):

A pesquisa bibliográfica é desenvolvida com base em material já elaborado, constituído principalmente de livros e artigos científicos. Embora em quase todos os estudos seja exigido algum tipo de trabalho desta natureza, há pesquisas desenvolvidas exclusivamente a partir de fontes bibliográficas.

Segundo Gil (2009), a leitura que se faz na pesquisa bibliográfica deve servir aos seguintes objetivos: identificar as informações e os dados constantes do material impresso; estabelecer relações entre as informações e dados obtidos com o problema proposto; analisar a consistência das informações e dados apresentados pelos autores.

A discussão dos termos memória organizacional, memória social e memória institucional está em andamento, visto que faz parte do projeto de pesquisa “A memória 
e a constituição de bases de conhecimento nos ambientes institucionais". O levantamento dos termos apresentados e discutidos permitirá uma melhor compreensão dos conceitos utilizados pelas várias áreas do conhecimento científico, propiciando um enriquecimento no embasamento teórico da pesquisa em questão.

Nesta etapa da pesquisa, foram consultados livros e artigos científicos referentes ao tema da pesquisa propondo assim uma análise de diversos conceitos, uma vez que este tipo de pesquisa permite ao pesquisador uma cobertura ampla do contexto abordado, auxiliando também na investigação histórica que será trabalhada.

\section{Considerações Parciais}

O objetivo do presente trabalho foi apresentar ao leitor, um quadro das principais áreas que trabalham com a memória. Como mencionado anteriormente, a discussão dos termos apresentados no presente trabalho não está finalizada, porém percebe-se que várias áreas do conhecimento científico estudam as questões relacionadas à memória, cada qual com suas interfaces, características e especificidades.

Isso ocorre pelo fato de o homem ser formado não somente por sua condição biofísica-eletro-química, mas também por seu contexto social, histórico e cultural, isto é, o tempo e o espaço, a lembrança e o esquecimento também fazem parte dessa formação.

No contexto psicológico, biológico e físico, a memória humana tem características peculiares, que somente o homem possui, apresentando uma estrutura cerebral complexa, relacionados a fatores como aprendizagem, atenção entre outros. Diante desta complexidade, diferentes áreas do conhecimento têm trabalhado com memória, conforme já discutido. Contudo, o que se deve considerar é no quê cada área pode contribuir, dentro do seu contexto de pesquisa/conhecimento, para uma melhor compreensão do homem e sua memória.

Quando tratamos com o fator social, temos as Memórias Social e Coletiva, estudadas pelas áreas da Ciência da Informação, Filosofia, História entre outras. Todavia, o indivíduo, que faz parte do social, tem sua memória individual. Assim, de acordo com 
Holanda (2011) a memória individual terá um papel importante, quando recorremos à questão da memória coletiva, tema discutido com profundidade por Maurice Halbwachs. Porém, a autora defende que o indivíduo, quando toma contato com qualquer informação, está frente a uma massa de conhecimento que representa as informações de toda uma coletividade, pertencente a um dado tempo histórico. De tal modo, estas informações, quando internalizadas pelo indivíduo, produzem um efeito, fazendo-o buscar outras fontes de informação que possibilitarão suplementar sua necessidade ou curiosidade motivada pela informação inicial pela qual tomou contato.

Além disso, o uso de narrativas (ou do saber passado verbalmente) auxilia a humanidade a apropriar-se de informações, possibilitando responder as mais diversas situações cotidianas, construir e reconstruir conhecimento, para o uso das futuras gerações. Dentro deste processo cumulativo de informações, está presente o sujeito cognoscente, e quando este é considerado dentro do processo, ou seja, fazendo parte da produção e acumulação de informações, a mensagem, que é socialmente transmitida, ganha status de memória (SHIKIDA; MOURA, 2010).

Holanda (2011), em seus estudos relacionados à memória no contexto da $\mathrm{Cl}$, confirma que esta área do conhecimento tem construído seu referencial teórico por meio da interdisciplinaridade. Percebe-se que na França e na Itália, os estudos são voltados à área da Comunicação Social (Semiótica), da História Social (estudos subalternos e a micro-história), e inclusive da Biologia (códigos genéticos).

Com o levantamento e análise do material bibliográfico, observou-se também que os termos Memória Organizacional e Memória Corporativa são estudados pelas áreas da Administração e de Sistemas de Informação (Ciência da Computação), sendo utilizados como sinônimos. Outros termos também são utilizados: base de conhecimento empresarial, memória de grupo, mente de grupo, memória coletiva, inteligência coletiva, inteligência corporativa, base de conhecimento compartilhado, repositório corporativo, banco de dados de know-how.

Nos ambientes institucionais, o conceito de MI é estudado, principalmente, por Icléia Thiesen Costa. Inicialmente, a autora faz uma diferenciação entre organização e 
instituição, para depois definir o termo MI. A autora, em seu trabalho mais recente, não limita o conceito de MI, visto que está em constante desenvolvimento e estruturação, englobando a instituição como um todo, sendo formada com o passar do tempo. Além disso, também defende que a MO faz parte da MI, ou seja, a MI é maior do que a MO. Porém, o que se encontra na literatura, de forma geral, é o uso dos termos como sinônimos, necessitando-se, desta forma, uma delimitação do foco de cada tipo de memória. Ou seja, a instituição deverá analisar e definir o que irá fazer parte da $\mathrm{MI}$, e o que irá fazer parte da MO, principalmente em relação aos conteúdos/documentos de cada tipo de memória.

A área de Comunicação Empresarial também estuda a MI e seu entorno, porém tem como foco principal, a Memória Empresarial da organização, destacando a reflexão entre os aspectos econômicos, ideológicos e estruturais das empresas. Neste contexto, a preocupação maior é com a imagem que a organização passa à sociedade, promovendo, assim, a divulgação das suas produções e realizações, como defende Thiesen (2013).

De acordo com os estudos analisados, na sociedade oral, os conhecimentos eram passados, de geração a geração, na forma de rituais; na idade média, na forma de comemorações e construção de monumentos. Essas formas de transmissão do conhecimento, e consequente registro da memória, exigiam maior envolvimento do homem, o que poderia possibilitar melhor registro dos acontecimentos da época. Hoje, com o surgimento das Tecnologias de Informação e Comunicação, a geração de informação e construção do conhecimento é muito grande, e o homem pode não conseguir gerenciar todo este conteúdo. Além disso, o registro deste conteúdo pode ser dificultado pela falta de estruturação de tecnologias adequadas e apropriadas a registrar toda informação e conhecimento construído socialmente.

O que se percebe é que a área do estudo em tela, atualmente, é de grande valor, e ainda está em desenvolvimento. Nos últimos anos, com as grandes transformações pelas quais a sociedade tem passado, o tema tem sido discutido com maior profundidade, e muitas pesquisas têm sido realizadas, principalmente no tocante ao ambiente institucional e organizacional, foco da pesquisa "A memória e a constituição de bases de 
conhecimento nos ambientes institucionais". Todavia, defende-se também a importância dos estudos relativos às outras vertentes da memória, apresentados no texto.

\section{Referências}

ALMEIDA, Mauricio Barcellos. Um modelo de ontologias para representação da memória organizacional. Belo Horizonte: UFMG, 2006. Tese (Doutorado) - Programa de PósGraduação em Ciência da Informação - Universidade Federal de Minas Gerais (UFMG), Belo Horizonte, 2006.

BARBOSA, Andréia Arruda. O lugar da memória institucional nas organizações complexas. In: CONGRESSO BRASILEIRO CIENTÍFICO DE COMUNICAÇÃO ORGANIZACIONAL E DE RELAÇÕES PÚBLICAS, 4, de 20 a 22 de maio de 2010, Porto Alegre. Anais.. São Paulo: Abrapcorp, 2010. Disponível em:

<http://www.abrapcorp.org.br/anais2010/GT2/GT2_Andreia.pdf>. Acesso em: 25 ago. 2011.

BERGSON, Henri. Memória e vida. 2.ed. São Paulo: WMF Martins Fontes, 2011.184p.

COSTA, Icleia Thisen Magalhães. Memória institucional: a construção conceitual numa abordagem teórico-metodológico. Rio de Janeiro: UFRJ, 1997. Tese (Doutorado) Programa de Pós-Graduação em Ciência da Informação - Universidade Federal do Rio de Janeiro (UFRJ), Rio de Janeiro, 1997.

CRIPPA, Giulia. Memória: geografias culturais entre história e ciência da informação. In: MURGUIA MARAÑON, Eduardo Ismael. (Org.). Memória: um lugar de diálogo para arquivos, bibliotecas e museus. São Carlos: Compacta, 2010. p.79-110

DODEBEI, Vera Lucia Doyle Louzada de Mattos. Informação, memória, conhecimento: convergência de campos conceituais. In: ENCONTRO NACIONAL DE PESQUISA EM CIÊNCIA DA INFORMAÇÃO, 10., 2010. ANAIS... Rio de Janeiro: UFRJ, 2010.

DODEBEI, Vera Lucia Doyle Louzada de Mattos; GOUVEIA, Inês Cordeiro. Memória do futuro no ciberespaço: entre lembrar e esquecer. Rio de Janeiro, DataGramaZero. Revista de Ciência da Informação, Rio de Janeiro, v.9, n.5, out. 2008. Disponível em: <http://www.dgz.org.br/outo8/Art_02.htm>. Acesso em: 10 out. 2012.

ERLL, Astrid; NÜNNING, Ansgar. Cultural memory studies: an international and interdisciplinary handbook. Berlin; New York: Walter de Gryter, 2008. Disponível em: <http://www.let.leidenuniv.nl/pdf/geschiedenis/cultural\%2omemory.pdf>. Acesso em: 25 abr. 2011.

FENTRESS, James; WICKHAM, Christopher. Memoria social. Madrid: Cátedra, 2003. 262p.

FISCHER, Steven Roger. História da leitura. São Paulo: UNESP, 2006. 384p. 
FOSTER, Jonathan K. Memória. Porto Alegre: L\&PM, 2011.

GIL, Antônio Carlos. Como elaborar projetos de pesquisa. 4 ed. São Paulo: Atlas, 2009.175 p.

HOLANDA, Adriana Buarque de. Memória e esquecimento na ciência da informação: um estudo exploratório. Recife: UFPE, 2011. 142f. Dissertação (Mestrado) - Programa de PósGraduação em Ciência da Informação - Universidade Federal de Pernambuco (UFPE), Recife, 2011.

JUNG, Carl Gustav. O homem e seus símbolos. Rio de Janeiro: Nova Fronteira, 1991.

LE GOFF, Jacques. História e memória. 5. ed. Campinas: UNICAMP Editora, 2003.

LEHNER, Franz; MAIER, Ronald K. How can organization memory theories contribute to organizational memory systems? Information Systems Frontiers, v.2, n.3/4, p.277-298, 2000.

LÉVY, Pierre. As tecnologias da inteligência: o futuro do pensamento na era da informática. Rio de Janeiro: Editora 34, 1993. 208p.

LIEURY, Alain. A memória: do cérebro à escola. São Paulo: Ática, 1997. 111p.

MONTEIRO, Silvana Drumond; CARELLI, Ana Esmeralda; PICKLER, Maria Elisa Valentina. A Ciência da Informação, memória e esquecimento. DataGramaZero: Revista de Ciência da Informação, Rio de Janeiro, v.9, n.6, dez. 2008.

NASSAR, Paulo. Relações públicas na construção da responsabilidade histórica e no resgate da memória institucional das organizações. 2.ed. São Caetano do Sul [SP]: Difusão Editora, 2008. 206p.

NORA, Pierre. Entre memória e história: a problemática dos lugares. Revista Projeto História, São Paulo, n. 10, p. 7-28, dez., 1993.

OLIVEIRA, Eliane Braga. O conceito de memória na ciência da informação no Brasil: uma análise da produção científica dos programas de pós-graduação. 2010.196 fl. Tese (Doutorado) - Programa de Pós-graduação em Ciência da Informação - Universidade de Brasília, Brasília.

PINTO, Amâncio da Costa. Memória, cognição e educação: Implicações mútuas. In DETRY, B. ; SIMAS, F. (Eds.), Educação, cognição e desenvolvimento: Textos de psicologia educacional para a formação de professores (pp. 17-54). Lisboa: Edinova, 2001. p. 17-54.

POLLAK, Michael. Memória, esquecimento, silêncio. Estudos Teóricos, Rio de Janeiro, v.2, n.3, p. 3-15, 1989. 
RICOUER, Paul. A memória, a história, o esquecimento. Campinas: UNICAMP Editora, 2007.

ROSSI, Paolo. O passado, a memória, o esquecimento: seis ensaios da história das ideias. São Paulo: UNESP Editora, 2010. 238p.

SANTOS, Izequias Estevan dos. Manual de métodos e técnicas de pesquisa científica. 5.ed. Rev., ampl. e atual. Niterói [RJ]: Impetus, 2005.

SANTOS, Myrian Sepúlveda dos. Memória coletiva e teoria social. São Paulo: Annablume, 2003.

MELGAR SASIETA, Héctor Andrés; BEPPLER, Fabiano Duarte; PACHECO, Roberto Carlos dos Santos. A memória organizacional no contexto da engenharia do conhecimento. DataGramaZero: Revista de Ciência da Informação, Rio de Janeiro, v.12, n.3, ago. 2011. Disponível em: <http://www.dgz.org.br/ago11/F_I_aut.htm>. Acesso em: 10 set. 2011.

SHIKIDA, Aparecida Maciel da Silva. Informação, história e memória: a constituição social da informação em relatos orais. Belo Horizonte: UFMG, 2005. 157f. Dissertação (Mestrado) - Programa de Pós-Graduação da Escola de Ciência da Informação Universidade Federal de Minas Gerais (UFMG), Belo Horizonte, 2005.

SHIKIDA, Aparecida Maciel da Silva; MOURA, Maria Aparecida. Memória e redes sociais: informação e conhecimento em relatos orais. In: ENCONTRO NACIONAL DE PESQUISA EM CIÊNCIA DA INFORMAÇÃO, 8., 2007. Anais... Salvador: UFBA, 2007.

SIMÃO, Hugo Eduardo. Memória organizacional. Disponível em: $<w w w . b a t e b y t e . p r . g o v . b r / m o d u l e s / c o n t e u d o / c o n t e u d o . p h p ?$ conteudo=1716 $>$. Acesso em: 26 abr. 2010.

SPILLER; Arnaldo; PONTES, Cecília Carmen Cunha. Memória organizacional e reutilização do conhecimento técnico em uma empresa do setor eletroeletrônico no Brasil. RBGN, São Paulo, v.9, n.25, p.96-108, set./dez. 2007.

STEIN, E.W. Organizational Memory: review of concepts and recommendations for management. International Journal of Information Management, v.15, n.1, p.17-32, 1995.

TEIXEIRA COELHO NETTO, J. Semiótica, informação e comunicação. 6. ed. São Paulo: Perspectiva, 2003. 217p.

THIESEN, I. Informação, memória e história: a instituição de um sistema de informação na corte do Rio de Janeiro. Encontros Bibli: Revista Eletrônica de Biblioteconomia e Ciência da Informação, Florianópolis, n.esp., 1. Semestre, 2006. 
THIESEN, I. Memória institucional. João Pessoa: UFPB, 2013. 310 p.

TOTINI, B.; GAGETE, E. Memória empresarial, uma análise da sua evolução. In: NASSAR, P. (Org.). Memória de empresa: história e comunicação de mãos dadas, a construir o futuro das organizações. São Paulo: ABERJE, 2004. p.113-126

Recebido em: 25/06/2014 Aprovado em: 07/10/2014

Universidade do Estado de Santa Catarina - UDESC Centro de Ciências Humanas e da Educação - FAED

Revista PerCursos

Volume 15 - Número 29 - Ano 2014 revistapercursos@gmail.com 